vitriollösung nachgestrichen. Es bildet sich schwefelsaures Natron, das auswittert und vom Regen fortgespült wird, während das Kreosot zurückbleibt. Controlirende Versuche sollen sehr günstige Resultate gegeben haben. (Bl. fuir Hdl. u. Gewerbe. 1866. 7.)

$B$.

\title{
Schiesspulver aus Holzsägespänen
}

wird in der Pulverfabrik zu Potsdam dargestellt und wird die Fabrikation in kurzer Zeit auch in Frankreich eingeführt werden. Die Entdeckung rührt von Schultze, Artillerie-Officier in der preussischen Armee, her. Man erhält das Pulver durch Digestion von Holzsägespänen in Natronlauge, worauf man die mit Wasser gewaschene Mischung der Wirkung ron Dampf aussetzt. Nach Bleichen mit Chlor und neuem Waschen werden die Späne in eine Mischung von $40 \mathrm{Th}$. Salpetersäure und $100 \mathrm{Th}$. Schwefelsäure gebracht, der Ueberschuss der Säuren wird durch eine Turbine herausgeschleudert, die Holzmasse mit Natron gekocht, ausgewaschen und getrocknet. Das so erhaltene Product ist unschädlich und durchaus nicht brennbar, so dass man es in voller Sicherheit in die Magazine bringen kann. Um es explodirbar zu machen, digerirt man es 15 Minuten mit einer Jüsung von 12 Th. Pottasche in $100 \mathrm{Th}$. Wasser; das darauf nöthige Trocknen muss bei höchstens $40^{\circ} \mathrm{C}$. geschehen. Es hat dieses Pulver den Vorzug vor anderen explodirenden Compositionen, dass man es auf nassem Wege darstellen kann und dass es in dem Augenblicke, in welchem das Präparat fertig ist, keine Gefahr mit sich führt. Man versichert, dass es die Waffen niclit schmutzig mache und in guter Qualität sehr wenig Rauch gebe. Frankreich endlich würde, wenn es dieses neue Pulver annimmt, nicht mehr nöthig haben, Schwefel vom Auslande zu kaufen, und so eine jährliche Ersparniss von nicht weniger als 3 Millionen erzielen. (Courrier de la Côte. 1866.)

Dr. Reich.

\section{Collodiumwolle.}

Daws on's Versuche haben ergeben, dass selbst bei Beachtung aller Vorsichtsmassregeln nicht immer ein gutes Collodium erhalten wird, besonders ist die Qualität der Baumwolle und die Länge der Faser zu beachten. Langfaserige Baumwolle gab stets gutes Collodium, in demselben Säuregemische jedoch löste sich geringere wenn 